\title{
O espaço museológico pautado pelas perspectivas fenomenológicas e interdisciplinares
}

\author{
Luciana Pasqualucci $^{1}$
}

\begin{abstract}
Resumo
O presente texto busca ampliar a compreensão de como o espaço museológico pode colaborar para uma construção interdisciplinar do conhecimento. 0 trabalho objetiva evidenciar de que modo a interdisciplinaridade pode ser exercitada, bem como se pode justificar atualmente a construção de uma atitude interdisciplinar frente ao conhecimento. As noções da Fenomenologia e da Arte Contemporânea fundamentam a pesquisa. A interdisciplinaridade, ao enfatizar a importância da intersubjetividade e das parcerias, além de evidenciar seus cinco conceitos norteadores (humildade, respeito, coerência, espera e desapego), torna-se uma atitude que pode viabilizar as intencionalidades educativas e institucionais do museu, na tentativa de compartilhar seu patrimônio cultural e artístico junto ao público. A interdisciplinaridade, na condição de categoria de ação, pode concretizar, no espaço museológico, demandas institucionais e projetos educativos calcados numa visão fenomenológica de homem, o que significa compreendê-lo como ser criador, coletivo e questionador. Esse homem, que pergunta pelos sentidos das coisas, ao deparar-se com a produção contemporânea de arte no museu,
\end{abstract}

\footnotetext{
${ }^{1}$ Mestre e doutoranda em Educação: Currículo pela PUC-SP, graduada em Artes Plásticas pela Fundação Armando Álvares Penteado e especialista em Psicopedagogia pela PUC-SP. É Pesquisadora do GEPI - Grupo de Estudos e Pesquisas em Interdisciplinaridade - PUC/CNPq e desenvolve pesquisas sobre Estética e Fenomenologia desde 1999. Possui experiência na área de gestão e educação museológica, atuando principalmente nos seguintes temas: projetos interdisciplinares em museus, arte contemporânea, cursos de formação, ensino e aprendizagem e estratégias de mediação.

lucianapasqualucci@gmail.com
} 
pode construir conhecimentos articulando suas experiências às diferentes áreas do saber que permeiam as artes plásticas, agregando aos discursos conceituais aspectos da realidade. Ao considerar a realidade, o museu desempenha um importante papel social: gerar motivações e reflexões que continuem para além do espaço museológico.

Palavras-chave: Educação; interdisciplinaridade; fenomenologia; museus; arte contemporânea

\begin{abstract}
This paper seeks to increase the understanding how of museum can contribute to an interdisciplinary knowledge construction. The article aims to show how interdisciplinarity can be exercised, as well as you can now justify the construction of an interdisciplinary attitude to knowledge. The notions of Phenomenology and Contemporary Art underlie research. The interdisciplinarity, to emphasize the importance of inter and partnerships, and also highlights its five guiding concepts (humbleness, respect, coherence, expectation, and detachment), it is an attitude that can facilitate the educational and institutional intentions of the museum in an attempt to share their cultural and artistic heritage with the public. The interdisciplinarity in the category of state action can achieve in the museum, institutional demands and educational projects trampled a phenomenological view, which means to understand it as being creative, collective and questioning. This man, who question the sense of things, when faced with the contemporary art in the museum, you can build knowledge articulating their experiences to the different areas of knowledge that permeate the plastic arts, adding to the conceptual discourse aspects of reality. When considering the reality, the museum plays an important social role: generate motivations and reflections that continue beyond the museum.
\end{abstract}

Keywords: Education; interdisciplinarity; phenomenology; museums; contemporary art

\title{
INTRODUÇÃO
}

A fenomenologia é uma filosofia que instaura uma visão de homem e de mundo. Um mundo que precede a existência humana, que sempre esteve presente, que oferece 
possibilidades factuais, e que ora se mostra ora se vela às nossas percepções.

A fenomenologia pode evidenciar características importantes para trabalhar a produção de conhecimento no espaço museológico: o mundo como fenômeno contingente, a experiência como primazia do processo de conhecimento e a fundamental importância da relação do homem com o mundo, incluindo, aqui, seus pares no ato de conhecer.

A fenomenologia surge por um questionamento crítico epistemológico em que o matemático e filósofo alemão Edmund Husserl (1859-1938) procura discutir as perspectivas do pensamento cientificista, desenvolvendo seu pensamento na direção de uma produção de conhecimento que pudesse alcançar maior rigor do que a que ele considerava que era um rigor científico positivista (HUSSERL, 2000). Acreditava que toda ciência humana baseada na perspectiva positivista padecia de falta de rigor, pois criticava três vertentes pelas quais o conhecimento era efetivamente construído: o psicologismo, isso é, o conhecimento como derivado de uma subjetividade e organização psicológica; o sociologismo, pois o conhecimento seria produto social e o historicismo, no qual a produção de conhecimento seria o resultado de produtos históricos. Por essas perspectivas, Husserl não considerava o rigor da ciência como suficiente. Foi em busca desse rigor que desenvolveu a fenomenologia, procurando alicerçar-se numa percpectiva metodológica que possibilitasse, segundo Husserl, uma fundamentação da ciência que fosse o resultado de um movimento de "ir às coisas mesmas". Considerando a observação do fenômeno o princípio pelo qual qualquer produção de conhecimento ocorre, tenta fundamentar as bases metodológicas de sua proposta, considerando a observação e a experiência so sujeito. A cientificidade, alcançada quando se recorriam aos dados, seria, dessa maneira, levada às últimas consequências. Ir às coisas mesmas, aos dados mesmos, aos 
fenômenos mesmos, eis a proposta da fenomenologia. A experiência, os fenômenos como aparecem de modo originário, sem mediações teóricas. Por meio da fenomenologia, Husserl pretendia desenvolver uma ciência universal, que abordasse o objeto não por meio de abstrações, mas pelo que ele é.

A primeira condição da fenomenológica é a eliminação da subjetividade, o que Husserl denomina de redução eidética (eidos). É um anseio de superar o psicologismo. Elimina-se a subjetividade quando se descreve o ato intencional. O objeto nos afeta, mas não operamos sobre ele. Estuda-se o fenômeno para além da subjetividade. Suspende-se a subjetividade e as perspectivas teóricas, considerando, primeiro, o fenômeno, e não a explicação sobre ele. Antes percebemos, depois transformamos em conceito. Suspender nossas crenças sobre o fenômeno interrogado, ou realizar a epoché, é buscar abstrair-se de qualquer teoria, pressuposto ou hipótese. É entrar em contato com o fenômeno e apreender como ele é do modo como ele se mostra, sem expectativas e juízos de valor.

A interdisciplinaridade fundamenta-se, inicialmente, na fenomenologia (FAZENDA, 2006). Ambas consideram o homem o responsável pela produção de significados, mas, diferentemente desta, que se realiza como concepção, aquela acontece na ação. Enquanto a fenomenologia respalda o pensamento acadêmico em relação a importância de considerar experiência e a percepção como fundantes da racionalidade, a interdisciplinaridade acontece na e pela experiência, no estado de interrelação e interação do homem com o coletivo e com os demais fenômenos. Pode-se afirmar, nesse contexto, que exercer a interdisciplinaridade é praticar a fenomenologia. E, por conseguinte, que praticar a fenomenologia seja exercitar a interdisciplinaridade (PASQUALUCCI in FAZENDA, 2014, p. 118).

Fazenda (2011) atribui à comunicação um papel importante, na medida em que procura interpretar, explicar, compreender e modificar. Relacionamos essa potência atribuida 
à comunicação às possibilidades comunicativas que experimentamos no espaço museológico, em que o sujeito, ao exercitar sua autoria, "compreende a si próprio e torna-se um novo ser no mundo" (idem, p. 57).

\section{FENOMENOLOGIA}

Pensar atualmente sobre essa perspectiva de produção de conhecimento inaugurada por Husserl é também pensar sobre a impossibilidade de uma prática. O afastamento, feito por nós, das nossas próprias crenças e valores pode nos parecer impossível. Por que então considerar a fenomenologia? Por que pensar sobre ela? Por acreditar no protagonismo do homem na produção de sentidos e na sua responsabilidade em traçar os caminhos da própria existência. Por vislumbrar que, na relação com a produção contemporânea de arte, em que seus significados não estão prontos e, mais do que isso, sugerem e abrem espaços para reflexões sobre fenômenos cotidianos e possibilidades futuras, a concepção fenomenológica de homem e de mundo auxilia no desenvolvimento de estratégias educativas e institucionais que favoreçam a aproximação do sujeito com a arte e tornem o espaço museológico um espaço coletivo onde o diálogo, os diversos saberes e o encontro com a diversidade propiciem a construção de um conhecimento interdisciplinar. A fenomenologia, como discurso que abre possibilidades, encontra na interdisciplinaridade certa proposição prática.

$\mathrm{E}$, se o museu aborda questões inerentes à condição humana, e a condição humana é corporal, considerar a fenomenologia é perceber o sujeito que visita o museu como um corpo encarnado, campo de percepção e de ação; corpo que habita o espaço (MERLEAU-PONTY, 1992).

A fenomenologia não possibilita falar do mundo de um ponto de vista externo ao próprio corpo, antes de sua origem na experiência perceptual. Isso não significa que o mundo permaneça no campo privado da experiência de cada um, mas, 
sim, que a percepção é o primado da experiência. Ainda segundo Merleau-Ponty (1999), há sempre um polo da experiência centrado no indivíduo, que percebe, e outro centrado no que é percebido. A percepção é o encontro entre as forças de ambos. A fenomenologia, assim, concebe o homem como ser que vive posicionado pela percepção e, ela, por sua vez, demanda do ser humano uma posição paradoxal, que é apreender os fenômenos objetiva e subjetivamente. Essa dimensão exige a coexistência do objetivo e do subjetivo para que o si mesmo possa acontecer de maneira integrada.

A concepção fenomenológica de homem, como ser postado na primazia do ato perceptivo, que apreende as coisas num campo objetivo e estabelece relações entre a apreensão e sua vida de um modo pessoal, considera-o como um ser em ação, em devir, que pergunta pelos sentidos das coisas. A compreensão do ser humano como um ser interrogativo e ativo, que impõe rupturas, cria o inédito e possibilita a constituição de si, do outro e do mundo relaciona-se à compreensão do ser humano como criativo e livre: ser criativo, ser de liberdade, de responsabilidade (de responder à sua existência), ser que emerge como ruptura. Visto sob essa perspectiva, o ser humano acontece em meio à precariedade e ao desamparo, o que faz com que ele necessite do acolhimento do outro. Ser homem é acolher o semelhante em sua jornada de significações e ser acolhido pelos demais em sua chegada ao mundo.

A fenomenologia considera o mundo percebido como o fundante dos sentidos que o humano constrói à sua existência e aos fenômenos com os quais se depara, alçando como facetas originárias da condição humana a percepção, a intencionalidade, o gesto e a condição de ser em devir. Isso entendendo origem como aquilo a partir do qual e por meio do qual uma coisa é o que é, e como é (HEIDEGGER, 1992). Nesse sentido, a experiência do estabelecimento de si mesmo é a experiência de perceber, criar, conviver (SAFRA, 2004). As experiências no espaço do 
museu, disparadas pelo objeto ${ }^{2}$ de arte, provocam essa experiência do estabelecimento do si, em que o perceber, o criar e o conviver acontecem de maneira integrada. A fenomenologia contribui para a construção de uma visão interpretativa em decorrência da percepção livre de preconceitos e expectativas. É na relação com o objeto de arte que podemos praticar a epoché. A fenomenologia embasa, na investigação aqui apresentada, como fito de uma construção interdisciplinar do conhecimento, a possibilidade do sujeito visitante do museu apreender o objeto de arte por meio de suas características perceptuais, para, posteriormente, fazer uso subjetivo de suas referências, a fim de que a arte dê a sua contribuição na condição de metáfora epistemológica (ECO, 1976). A arte como metáfora pode ser entendida por um objeto visual e conceitual, carregado de estímulos estéticos, que produz uma reação em cadeia, na qual a produção de significados quanto à forma disparadora desses sentidos (obra) torna-se tão originária quanto aquilo que ela pode dizer para o sujeito. Eis uma concepção fenomenológica da relação do sujeito com o espaço museológico.

Para pensarmos estratégias e ações que viabilizem a prática dessa concepção, é preciso buscar referências de como o sujeito constroi seu conhecimento. A fenomenologia nos ensina uma visão de mundo, e não a prática dela.

A fenomenologia enfatiza a importância da percepção no ato de conhecer, movimento que pode ser praticado no museu, na ocasião em que o sujeito se depara com um objeto de arte inusitado.

A percepção refere-se originariamente às experiências sensíveis e originárias. "O sujeito da sensação (...) é uma

\footnotetext{
${ }^{2}$ O conceito de objeto foi inaugurado pelo teórico e crítico de arte Ferreira Gullar, na década de 1960, ao perceber que o termo objeto poderia auxiliar a denominação de uma obra que não se enquadrava em nenhuma das categorias tradicionais da arte.
} 
potência que co-nasce em um certo meio de existência ou se sincroniza com ele" (MERLEAU-PONTY, 1999, p. 285). No museu, uma das primeiras experiências possíveis é a relacionada à visão. O apelo tátil, existente em muitos dos trabalhos, não pode ser usufruído por cuidado e preservação das obras. Tal tatilidade visual vem acompanhada de uma síntese visual. Essa síntese, sob a forma de objeto artístico, não se fecha em si, mas abre um horizonte de possibilidades. A consciência do sujeito é, então, dirigida para algo que se abre. "O mundo é aquilo que nós percebemos, não sendo aquilo que eu penso, mas o que eu vivo. Estamos abertos para o mundo, em comunicação com ele, mas não o possuiremos, pois é infinito" (MARTINS, 1992, p. 61). Este sistema de aparências, constituido pelo objeto de arte, pela disposição espacial onde está inserido etc., faz com que nenhuma análise verbal esgote suas possibilidades significativas.

Segundo Merleau-Ponty, "a cultura nunca nos oferece significações absolutamente transparentes, a gênese do sentido nunca está terminada" (1949, p. 70). Ou seja, o sentido é construído sob a atmosfera sensorial na qual o objeto em evidência mostra-se. Trata-se de uma atividade perceptiva. A percepção ilustra a ideia de consciência subjetiva (MERLEAUPONTY, 1999), que é um estado de alerta para o mundo e para o esclarecimento do mundo.

Falar em consciência, sob a ótica da fenomenologia, é mencionar a intencionalidade, o rigor do pensar. Intencionalidade como direcionalidade da consciência. A experiência e a intenção de significá-la são consequências daquilo que foi percebido. Desde essa perspectiva, as contribuições do espaço museológico para a construção de conhecimentos materializam-se ao ser estabelecida a relação entre o mundo que se apresenta - no caso, uma síntese em forma de objeto - e a consciência do sujeito. No museu, a direcionalidade da consciência volta-se para objetos que são resultados e apresentações de fenômenos do mundo. São 
objetos intencionais, pelos quais a consciência os atinge com atos de significação. Husserl (2000) discorre sobre a consciência intencional, consciência que se dirige a algo. Merleau-Ponty (1999) amplia o sentido da intencionalidade, estendendo-a para o corpo do sujeito, e procura mostrar que a área do pensamento é algo como uma experiência pré-reflexiva do corpo, que capacita o sujeito a transcender o imediato, o percebido, e a estrututar o mundo por meio de significações. "O sujeito da sensação não é nem um pensador que nota uma qualidade, nem um meio inerte que seria afetado ou modificado por ela; é uma potência que co-nasce em um certo meio de existência ou se sincroniza com ele" (MERLEAU-PONTY, 1999, p. 285).

Ao tomar contato com os pressupostos da fenomenologia, notamos que o espaço do museu pode ser considerado, in loco, um espaço fenomenológico. De acordo com Merleau-Ponty (1999), são as percepções da pessoa que definem os limiares de troca com o mundo. Martins (1992, p. 59) destaca três elementos neste processo:

- a percepção assume a primazia no espaço reflexivo;

- a consciência que se direciona para o mundo-vida, isto é, consciência do corps propre, ou seja, do corpo vivido, consciência que é descoberta da subjetividade e da intersubjetividade;

- o sujeito, pessoa ou indivíduo que se vê capaz de experienciar o corpo vivido, por meio da consciência, que é a conexão entre o indivíduo, os outros e o mundo.

O museu é mais do que um espaço institucional, social e cultural, constituído pela soma dos objetos que apresenta em suas exposições. É um espaço que evidencia a dimensão da existência. É um campo permanente em que o ser-para-si encontra o ser-no-mundo (MERLEAU-PONTY, 1999). Refletir aspectos da fenomenologia para a interdisciplinaridade, no espaço museológico, é buscar uma estrutura de pensamento que 
considere o sentido imanente e transcendente da arte contemporânea, a contingência da realidade e a participação do sujeito no vislumbrar de novas perspectivas.

\section{INTERDISCIPLINARIDADE}

O trabalho em parceria com instituições culturais e educacionais, bem como junto a profissionais de outras áreas do saber, com a finalidade de pesquisar relações possíveis entre arte e sujeito, além de realizar ações que atraíssem o público, trouxeram-me a indagação sobre o conceito de interdisciplinaridade decorrente dessas práticas. Acreditamos que a arte e as ações educativas realizadas no museu mobilizam em si, de modo imanente, diversas áreas do conhecimento. Mas uma ação interdisciplinar seria aquela que reúne diferentes áreas do conhecimento? Poderia existir interdisciplinaridade em uma única disciplina? Como seria a atitude do educador/gestor/propositor interdisciplinar? Para a realização de um projeto interdisciplinar, a instituição também precisaria ser interdisciplinar? O que seria e como funcionaria uma instituição interdisciplinar?

Debruçando-se sobre a obra de Ivani Fazenda (2011), evidencia-se a possível aproximação entre interdisciplinaridade e algumas das ações desenvolvidas pelos museus. Reconhecem-se algumas das ações realizadas no espaço museológico como essencialmente interdisciplinares, pois elas, fundadas na parceria e na busca pela inovação, promovem uma transformação na consciência dos idealizadores e dos participantes das ações. Ao elaborarmos junto aos nossos parceiros projetos cuja intencionalidade é apropriação do espaço museológico por parte do público, auxiliando-o a integrarem-se em um contexto, um lugar, atrelamos necessidades diferentes a um único objetivo. Atuamos, desta maneira, de modo interdisciplinar? Pensamos que sim. Reconhecer a complexidade do mundo atual é partilhar 
da necessidade da presença da interdisciplinaridade em nossas vidas.

Fazenda (2002) partilha da ideia de ambiguidade nos projetos interdisciplinares. Acreditamos que tal ambiguidade é condição para a interdisciplinaridade porque esta é ambígua por excelência. Ao mesmo tempo em que é simples, porque considera os eventos da realidade e acontece no fluxo da vida, torna-se complexa por esse mesmo motivo. Reconhecer a complexidade do mundo atual é partilhar da necessidade da presença da interdisciplinaridade em nossas vidas. Buscar a interdisciplinaridade é buscar a parceria, a intersubjetividade, a coerência e o desapego - este no sentido de suspendermos nossas crenças e valores para percebermos o que acontece à nossa volta de acordo como as coisas apresentam-se. Segundo Fazenda, "cinco princípios subsidiam uma prática docente interdisciplinar: humildade, coerência, espera, respeito e desapego" (2002, p. 11).

A Humildade está relacionada ao reconhecimento dos próprios limites. "Aceitar que sabe algo de modo imperfeito, incompleto, que, a qualquer momento, pode ser questionado, reformulado e mesmo superado" (FAZENDA, 2002, p. 64). Entrar em contato com nossa condição humana de imperfeição e inacabamento. $\mathrm{O}$ ato de humildade valoriza o saber do outro. Praticar a humildade é despir-se da arrogância e da superioridade. Nesse sentido, uma pessoa humilde conquistou, antes de tudo, uma qualidade fundamental na busca de suas realizações pessoal e professional: a autoconfiança.

A Coerência é o princípio que busca a conexão entre o pensar, o sentir e o agir dos indivíduos envolvidos em um projeto, uma ação. A articulação coerente entre os diferentes saberes, olhares, falas e gestos deve ser almejada em toda prática que se propõe interdisciplinar. De acordo com Giacon, "é a coerência que dá consistência ao olhar, o agir a ao falar, que faz com que o desejo individual adquira tamanha força que seja 
capaz de contaminar e se transformar em vontade coletiva que se realiza" (FAZENDA, 2002, p. 37).

A Espera é princípio também relacionado ao reconhecimento de nossos limites. Mais uma vez, destacamos a condição humana de finitude e incompletude. Esperamos, porque não podemos ter o que queremos, no momento em que o queremos, da maneira como o queremos. Dependemos do contexto em que vivemos: das pessoas, dos acontecimentos que fogem a nosso controle. A espera está relacionada à maturidade dos acontecimentos e das pessoas. "O tempo da ESPERA também é um tempo de leveza. Requer paciência e sabedoria, porque é um tempo de maturidade" (CASINO in FAZENDA, 2002, p. 108).

O Respeito é a base para uma convivência com paz. $O$ respeito à diversidade e às diferenças é fundamental para vivermos juntos. O Relatório para a UNESCO da Comissão Internacional sobre Educação (DELORS, 2001, p. 97) aponta o desafio que o aprender a viver juntos representa. Uma das possibilidades apontadas para amenizar os conflitos decorrentes da convivência entre pessoas e povos diferentes seria a descoberta progressiva do outro e a participação em projetos comuns para que a hostilidade e o preconceito cedam lugar à cooperação, ou seja, é preciso respeitar e incentivar o convívio na diversidade. A parceria - categoria maior da interdisciplinaridade (FAZENDA, 2002, p. 22) - só pode ser efetivada se houver respeito e confiança.

O Desapego é o princípio que permite enxergar um fenômeno pelo olhar do outro. Ao recebermos cada palavra ou gesto do sujeito como manifestação de seus valores e saberes, seremos capazes de compreendê-lo antes de o julgar. O desapego suspende nossas crenças, bem como as teorias que nos respaldam, para abrir espaço ao que nos apresenta o fenômeno. $\mathrm{Na}$ interdisciplinaridade, o desapego ensina-nos a escutar, olhar e perceber o outro e em que ele nos afeta antes mesmo de qualquer juízo de valor. O desapego é condição 
essencial para viabilizar a troca, a construção de novos conhecimentos e a estruturação de parcerias.

Fazenda (2011, p. 89), ao enfatizar que "a interdisciplinaridade não é categoria de conhecimento, mas de ação", oferta indícios de que é necessária, por parte daquele que pratica a interdisciplinaridade, certa atitude:

Atitude de busca de alternativas para conhecer mais e melhor; atitude de espera perante atos nãoconsumados; atitude de reciprocidade que impele à troca, ao diálogo com pares idênticos, com pares anônimos ou consigo mesmo; atitude de humildade diante da limitação do próprio saber; atitude de perplexidade ante a possibilidade de desvendar novos saberes; atitude de desafio diante do novo, desafio de redimensionar o velho; atitude de envolvimento e comprometimento com os projetos e as pessoas neles implicadas; atitude, pois, de compromisso de construir sempre da melhor forma possível; atitude de responsabilidade, mas sobretudo de alegria, de revelação, de encontro, enfim, de vida. (2007, p. 1314).

Esta atitude pode estar pautada nos cinco princípios, além da "busca do percurso teórico pessoal de quem se aventurou a tratar questões desse tema" (FAZENDA, 2011, p. 13). A interdisciplinaridade considera o vivido, o presente, a relações, o visível, o invisível, o pensado, o praticado, o falado e o indizível.

A fenomenologia e sua visão de homem e de mundo podem orientar o desenvolvimento do trabalho interdisciplinar no espaço museológico, pautado pela perspectiva de que o museu e a arte contemporânea: disparam questões; possibilitam antecipações; estabelecem relações; compartilham ideias; questionam; apresentam possibilidades; incentivam a interação entre os sujeitos e seus saberes; incentivam a integração entre as disciplinas; retiram o sujeito da obviedade; consideram a 
pluralidade de ideias; instauram novas formas de compreensão; ofertam a consciência valores humanos e relativos à cidadania; favorecem o protagonismo do sujeito; refletem fenômenos do mundo; são fenômenos do mundo; são instrumentos de investigação crítica do conhecimento; comunicam; subvertem; representam a ambiguidade presente no mundo por meio dos sentidos imanentes e transcendentes à arte contemporânea.

O sujeito, ao apropriar-se das relações sugeridas pelo objeto de arte, volta-se a ele para encontrar as razões desta sugestão. Esse movimento entrelaça os sentidos disparados pela arte pela provocação às qualidades estéticas da obra, mas também evoca um compartilhar de significados. "Assim, na dialética entre obra e abertura, o persistir da obra é garantia das possibilidades comunicativas e ao mesmo tempo das possibilidades de fruição estética" (ECO, 1976, p. 176).

Segundo Grinspum,

O conceito de Educação para o Patrimônio pode ser entendido como formas de mediação que propiciam aos diversos públicos a possibilidade de interpretar objetos de coleções dos museus, do ambiente natural ou edificado, atribuindo-lhes os mais diversos sentidos, estimulando-os a exercer a cidadania e a responsabilidade social de compartilhar, preservar e valorizar patrimônios com excelência e igualdade. A arte, enquanto bem patrimonial, tornando-se acessível a todos -por meio de metodologias adequadas à fruição, compreensão em sua multiplicidade de sentidos e estímulo à criação, revelará modos distintos de conhecimento. Os métodos serão muitos e sempre adequados às realidades de cada instituição, de cada acervo, de cada educador envolvido. Independente da tipologia do museu, o conceito de Educação para o Patrimônio poderia ser assumido para todos eles. (2000, p. 27) 
Grossmann observa "o papel dos museus de arte tem sido discutido a partir de pontos de vista estanques: poucos são os esforços para se procurar uma visão mais ampla envolvendo questões culturais e metodológicas" (2001, p. 132).

Suano afirma que "o museu deveria ser um importante veículo coletor de problemas, o lugar privilegiado onde a população os discutisse e fórum de decisões sobre a vida urbana" (1986, p. 73), apresentando a atitude interdisciplinar, segundo o nosso entendimento a partir de suas palavras, como necessidade intrínseca ao profissional de museus:

Uma das principais características do profissional do museu e que deveria ser tratada com seriedade em todos os cursos de formação é a capacidade para reelaboração cultural. Isto é, o profissional de museu deveria compreender e absorver a cultura local, participando ativamente das ocorrências políticas, econômicas, científicas, sociais e reelaborá-las na prática, na sua área de especialidade científica. (1986, p. 82)

Ou seja, a concepção de museu como espaço em potencial para compartilhar a cultura não é originária neste estudo. A preocupação aqui apresentada é de como fazer isso. De que modo podemos exercitar a interdisciplinaridade no museu? A interdisciplinaridade pode acontecer no ato educacional e também no trabalho de gestão?

É às vezes na perseverança de alguém em tentar recorrer a outra fontes do conhecimento para compreender a complexidade de um eixo teórico ou de um problema surgido na prática, que o indivíduo consegue perceber-se interdisciplinar. É no grau de envolvimento que o problema o conduz, na forma aberta como se dispõe a discuti-lo ou na paciência da espera para comprender facetas insuspeitadas de 
ângulos ainda por conhecer que o indivíduo consegue perceber-se interdisciplinar. (FAZENDA, 2011, p. 78)

As experiências no espaço museológico, na área de gestão, coordenação e educação, evocam a interdisciplinaridade no sentido de que ela pode ser considerada (FAZENDA, 2007, p. 32):

- como meio de conseguir uma melhor formação geral, pois somente o enfoque interdisciplinar pode possibilitar certa identificação entre o vivido e o estudado, desde que o vivido resulte da inter-relação de múltiplas e variadas experiências;

- como meio de atingir uma formação profissional, já que permite a abertura a novos campos do conhecimento e novas descobertas;

- como incentivo à formação de pesquisadores e de pesquisas;

- como condição para uma educação permanente, posto que através da subjetividade, característica essencial da interdisciplinaridade, será possível a troca de experiências;

- como forma de compreender e modificar o mundo, pois sendo o homem agente e paciente da realidade do mundo, torna-se necessário um conhecimento efetivo dessa realidade em seus múltiplos aspectos;

- como superação da dicotomia ensino-pesquisa.

Pesquisar e exercitar a atitude interdisciplinar em museus e espaços culturais significa indagar as certezas e praticar a cooperação, o diálogo, a humildade e o desapego e exercitar a reflexão. Fenomenologicamente, exercitar a interdisciplinaridade no espaço museológico significa considerar o sujeito visitante como um campo de percepção e de ação (MERLEAU-PONTY, 1999).

No final de ano de 2012, a Coordenação de Aperfeiçoamento de Pessoal de Nível Superior (CAPES) ${ }^{3}$ -

\footnotetext{
${ }^{3}$ A Coordenação de Aperfeiçoamento de Pessoal de Nível Superior (CAPES) é uma agência pública de pesquisa do Brasil vinculada ao Ministério da
} 
promoveu o encontro acadêmico internacional Interdisciplinaridade e Transdisciplinaridade no Ensino, Pesquisa e Extensão em Educação, Ambiente e Saúde ${ }^{4}$, com os objetivos de:

- Sistematizar o debate sobre aspectos teórico-conceituais que fundamentam a inter e a transdisciplinaridade como concepções de produção de conhecimento e de práticas,

- Promover a articulação da Educação Superior (pós-graduação e graduação) com a Educação Básica por meio de estratégias pedagógicas que potencializem a apropriação do conhecimento científico e tecnológico,

- Fomentar a inter e transdisciplinaridade como concepção fundamental para o estudo dos fenômenos complexos em todas as áreas do conhecimento, institucionalizando-a nas práticas de ensino, pesquisa e extensão na graduação e na pós-graduação brasileiras.

As discussões foram norteadas pelas seguintes questões:

1) Como os referenciais teórico-conceituais que fundamentam a inter e transdisciplinariedade dão suporte à produção de conhecimento e de práticas?

2) Como as diversas áreas do conhecimento podem incorporar a perspectiva inter e transdisciplinar no ensino, pesquisa e extensão atendendo às prioridades do país em Educação, Ambiente e Saúde?

3) De que maneira a interdisciplinariedade contribui para a articulação entre diferentes níveis de ensino que potencializem a apropriação do conhecimento científico e tecnológico visando melhoria da Educação Básica?

Educação que atua na expansão e consolidação dos cursos de Pós-Graduação stricto sensu em todos os estados do país

4 Disponível em: <http://seminarios.capes.gov.br/images/stories/conteudo Encontro/Programacao-Encontrolntern-nov12-Port.pdf >Acesso em: $30 \mathrm{abr}$ 2014. 
4) Como desenvolver perfis e práticas inter e transdisciplinares nos diversos níveis de formação, preparando indivíduos aptos para enfrentar os principais desafios contemporâneos?

Na palestra Inter e transdisciplinaridade como concepção de ensino, pesquisa e extensão, o Prof. Dr. Yves Lenoir (Université de Sherbrooke/Canadá) aponta a necessidade de fomentar a criatividade e postergar a especialização, daí a urgência em reformas profundas na educação.

Ao discutir o aprendizado de forma interdisciplinar ressaltou a importância de se atentar para o fato de que o mesmo se dá de forma diferente nas diferentes culturas, exemplificando com pesquisa realizada entre franceses, americanos e brasileiros. Neste sentido, é preciso pensar a interdisciplinaridade como um meio de garantir a integração do aprendizado entre os fundamentos teóricos e sua aplicabilidade prática, o que dá sentido ao conhecimento produzido. Fundamentou ainda, que é preciso pensar a interdisciplinaridade nas dimensões científica, prática, escolar e profissional. Assim, o currículo deve ser estabelecido por disciplinas que dialoguem entre si. Não se trata de adição, mas de manter uma relação que dará consistência a um currículo integrador onde o ensino e a aprendizagem, nessa perspectiva, integram os resultados com os saberes. As disciplinas passariam a ter três perspectivas complementares, quais sejam: construção da realidade, expressão da realidade 
e o estabelecimento de relação com essa realidade. Esta é a escola que formará cidadãos. ${ }^{5}$

Destacamos a possibilidade de articular com essa nova perspectiva de produção de conhecimento a parceria com os museus, a qual, por meio de ações culturais que abarquem a diversidade de conteúdos imanentes aos objetos de arte, possa colaborar com a implementação deste novo currículo integrador. Ao elaborar um discurso que sustente a materialidade do objeto de arte, exercitamos, na articulação de conceitos, uma fundamentação pautada naquilo que se sabe e naquilo que se aprendeu. O espaço museológico é uma construção da realidade, expressão da realidade e o estabelecimento de relação com essa realidade. Ao considerar a realidade, o museu desempenha um importante papel social, que é gerar motivações e reflexões que continuem para além do espaço museológico.

A palestra Experiências inter e transdisciplinares no ensino, pesquisa e extensão, proferida pelos professores Johann Koeppel (Technische Universität Berlin/Alemanha); Teresinha Froes Burnham (UFBA); Pedro Geraldo Pascutti (CA Interdisciplinar), destacou a necessidade de considerarmos as disciplinas sem atribuir maior grau de importância à alguma delas.

A interdisciplinaridade seguirá em crescimento porque os problemas concretos das populações não se enquadram na divisão tradicional dos campos científicos, sendo necessárias articulações com os órgãos de fomento em pesquisa para contemplarem melhor as áreas interdisciplinares. O enfoque inter e transdisciplinar é a evolução natural de todas as áreas do conhecimento. Para que esta evolução se concretize é necessário considerar que não existe

\footnotetext{
${ }^{5}$ Relatório Síntese disponível em: http://seminarios.capes.gov.br/images/stories Lconteudo/ Encontro/ relatorio sintese final.pdf . Acesso em: 30 abr 2014
} 
hierarquia entre as ciências, e, portanto, deve-se incluir todos os campos científicos.

Acrescentamos que, além das articulações com os órgãos de fomento para promover o diálogo entre as disciplinas, as questões suscitadas no espaço museológico, por meio da arte e da realização de projetos culturais e educativos, podem provocar este diálogo.

A parceria dos museus com universidades e centros de extensão e pesquisas, além de colaborar para a construção de um conhecimento interdisciplinar, pode também fazê-lo em favor do exercício da atitude interdisciplinar, para alcançarmos uma aprendizagem que considere a diversidade, a pluralidade dos saberes e a importância de uma convivência harmoniosa e produtiva entre os pares. O museu é um espaço de transformação, diálogo e valorização dos saberes individuais e coletivos. É um espaço em que o conhecimento que reúne diversas disciplinas, ofertado inicialmente pela Educação Básica, encontra saberes relacionados à condição humana, ao mundo, às angústias e felicidade inerentes ao viver.

De acordo com Gasparian:

Podemos vislumbrar o destino da educação: ter um papel fascinante e complexo no desenvolvimento da humanidade e voltar-se aos mais nobres objetivos de nossa existência, ou seja, nossa evolução. Não devemos apenas qualificar a geração futura para o mercado de trabalho, reverenciando valores passados, mas podemos conduzir essa nova geração futura a escolhas mais assertivas, desenvolvendo atitudes reflexivas sobre o que a sociedade nos oferece e o que de fato precisamos para alcançar ou o que realmente queremos. $(2008$, p. 35$)$

Um museu existe se contiver, em seu acervo, uma boa coleção, desenvolver bons projetos culturais e contar com a 
presença e a participação das pessoas da sociedade. As pessoas que visitam o museu e participam de suas atividades são sujeitos dos desafios que precisam ser enfrentados: o museu é um espaço de diálogo, de circulação de saberes, de encontro entre as diversas áreas do conhecimento, de produção de sentidos e local de estudo, de pesquisa e de difusão do conhecimento.

Segundo Coelho (1997), muitos museus, encontrando na ação educacional uma justificativa para existir e obter recursos, reforçam seus serviços escolares. Essa imagem educacional gera um efeito paradoxal: em vez de facilitar o acesso à arte, reforça a ideia de que o contato com a obra somente pode ser mediada por orientação. Surgem, então, duas perspectivas. A primeira considera o museu de arte tendo a função de reforçar uma determinada hegemonia cultural, geralmente a da cultura erudita, em que o melhor seria recusar a ideia do museu como extenção da escola. A segunda considera o museu com uma função democratizadora e que só pode ser cumprida com ações educativas. Ambas as visões acabam por restringir a discussão sobre o papel dos museus, que, vista pela hipótese inicial que motivou o desenvolvimento deste trabalho, pode ser muito mais do que facilitar a fruição da obra pelo visitante do museu, mediar os conteúdos da obra de arte, e muito menos a mera dependência dessa relação ou a finalidade econômica de sustento do museu e a viabilização dos demais projetos.

O museu, ao mesmo tempo em que preserva o patrimônio de uma sociedade, transforma-o quando amplia suas possibilidades significativas, reflexivas e discursivas para 0 público. Agregando às narrativas da arte contemporânea discursos "vivos" de indivíduos e comunidades, mais do que exibir sua coleção ou desenvolver projetos culturais, o museu passa a gerar questões sobre a realidade. Com esse movimento, o museu também passa a conhecer melhor a sua comunidade. $\mathrm{E}$ as pessoas, a perceberem o museu como parte de suas vidas. 


\section{REFERÊNCIAS}

BICUDO, M.A.V.; ESPÓSITO, V.H.C. (orgs.). Joel Martins... um seminário avançado em fenomenologia. São Paulo: Educ, 1997. COELHO, T. Usos da Cultura: políticas de ação cultural. São Paulo: lluminuras, 1997.

DELORS, J. Educação: um tesouro a descobrir. Relatório para a UNESCO da Comissão Internacional de Educação para o século XXI. $5^{\text {a }}$ ed. São Paulo: Cortez; Brasília, DF: MEC: UNESCO, 2001.

ECO. U. Obra Aberta. Forma e indeterminação nas poéticas comtemporâneas. São Paulo: Perspectiva, 1976.

FAZENDA, I.C.A. Interdisciplinaridade: História, Teoria e Pesquisa. Campinas: Papirus, 2011.

- Interdisciplinaridade: Um Projeto em Parceria. São Paulo: Loyola, 2007.

. Interdisciplinaridade: qual o sentido? São Paulo: Paulus, 2006.

FAZENDA, I.C.A. (org.). Interdisciplinaridade: pensar, pesquisar e intervir. São Paulo: Cortez, 2014.

- Interdisciplinaridade: Dicionário em construção. São Paulo: Cortez, 2002.

GASPARIAN, M.C.C. A Interdisciplinaridade como Metodologia para uma Educação para a Paz. Tese de doutoramento. Pontifícia Universidade Católica de São Paulo, 2008.

GRINSPUM, D. Educação para o patrimônio: Museu de Arte e Escola. Tese de Doutoramento. Universidade se São Paulo, Faculdade de Educação. São Paulo: 2000.

GROSSMANN, M. O Hipermuseu: A arte em outras dimensões. Tese de Livre Docência São Paulo: Universidade de São Paulo/Departamento de Biblioteconomia e Documentação da Escola de Comunicações e Artes, 2001.

HEIDEGGER, M. A Origem da Obra de Arte. (trad. Maria da Conceição Costa). Rio de Janeiro: Edições 70, 1992.

HUSSERL, E. A Ideia da Fenomenologia. Lisboa: Edições 70, 2000. 
MARTINS, J. Um Enfoque Fenomenológico do Currículo: Educação como Poíeses. São Paulo: Cortez: 1992.

MERLEAU-PONTY, M. Fenomenologia da Percepção. Trad. Carlos Alberto Ribeiro de Moura. São Paulo: Martins Fontes, 1999.

. O Visível e o Invisível. São Paulo: Perspectiva, 1992.

. O Olho e o Espírito. São Paulo: Cosac \& Naifi, 1949.

SAFRA, G. A Pó-ética na Clínica Contemporânea. São Paulo: Idéias e Letras, 2004.

SUANO, M. O que é Museu. São Paulo: Brasiliense, 1986. 